\title{
FREE OSCILLATION IN SURGE AND SWAY OF A MOORED FLOATING DRY DOCK
}

\author{
J. T. O"Brien and D. I. Kuchenreuther
}

Engineers, U. S. Naval Civil Engineering Research and Evaluation Laboratory Bureau of Yards and Docks, Department of the Navy, Port Hueneme, California

\section{SUMMARY}

Measurements are presented of the free perlod of oscillation in surge and sway of the AFDL-20 (floating dry dock with 2100 long ton displacement) and of the forces and movements induced. The Dock is spread moored fore and aft, respectlvel by one $1-1 / 2$ inch die lock chain about 260 feet long with rise of about 35 feet and scope of 8 . These measurements are compared with those obtained from osclllating a I to 40 linear scale model and from analytics and the agreement is pronounced good.

\section{INTRODUCTION}

For many years the Bureau of Yards and Docks has been concerned with resear on the forces induced on moored vessels by waves. In such a study -- unlike a largi number of those in the field of hydrodynamics which involve consideration of signifi cantly free or fixed objects -- the concern is with objects which are forced to move against the restraint of elastic type moorings.

Since, as in the hydrodynamics field in general, it is very rewarding to study at a reduced scale in the laboratory, it is necessary frequently to model the charac. teristics of the ships moorlngs as well as of the ship itself, where although the technique for the latter seems well established, that for the former is not.

To provide correlated data with which to evaluate the ability to model ships* mooring characteristics, a relatively small floating dry-dock, was spread moored in a simple manner, and a I to 40 linear scale model of it were caused to oscillate significantly in surge and sway in sensibly st ill water and the perlod of the free oscillations was measured. The results obtained from the model, as extrapolated to the Prototype by means of the Froude Model Law since inertlal forces seem dominan were compared with those obtained from the Prototype.

Because an analytical approach is desired in general, considerable attention was given also to the application of basic mechanics to provide a comparision with results obtalned from both the Prototype and the Model.

\section{TEST FACILITIES AND PROCEDURES}

\section{PROTOTYPE}

The vessel used is a floating drydock [AFDL-20 of 2100-long tons displacem1 


\section{FLOATING DRY DOCK}

(FIgure 1)] as moored in the harbor of Port Hueneme, California in about 35 feet of water by one chain, $1-1 / 2$ inch die lock of scope 8 , respectively fore and aft (Figure 2). Strain gage type dynamometers as described by $O^{\prime} B r i e n$ and Jones (1955) were used to measure chain tension at the Dock end.

By means of a tug temporarily attached to it, the Dock was displaced particular amounts in surge or sway as the case might be and then permitted to oscillate freely. The output from the chain dynamometers was recorded as a funtion of time so that direct measurement of both the chain tension and period of oscillation could be made. Movement of the Dock was determined as a function of time by means of direct reading by surveyors of the positions of scales attached to the Dock.

The in itial tension in the chains was varied during the experiments to provide a variation in the restoring force. This was done elther by waiting for the tide to vary the still water level or by changing the length of the chain. (Table I)

An attempt was made to conduct the experiments only when the wind, currents and waves were at a negligible level. In the case of the latter persistent surgesthose with about 1,3 , and 12 minute period - had to be tolerated but these, like the locally generated wind waves and the other environmental disturbances, were not considered to have affected adversely the results obtained. In no case was it possible to obtain pure surge or sway, so that coupling at what is considered a low level had to be tolerated.

Better results were obtained with surge where the restoring forces were relatively high and period and amplitudes short than with sway where the amplitudes were very long - of the order of 15-feet - and the motion died down after an oscillation or two due to the large form resistance and low restoring force involved.

\section{MODEL}

A I to 40 linear scale Model was constructed by the David Taylor Model Basin and balanced dynamically and moored by the University of California under a contract with the Bureau of Yards and Docks as described by Wiegel et al (1956). The Dock ends of the lines were fitted with dynamometers whose design and installation entailed considerable effort.

As in the Prototype the Model was displaced in elther surge or sway and then permitted to oscillate freely with force data recorded as a function of time so that the period could be deduced. Movements were not measured rigorouslys in some cases estimates of in itial displacement were made. 
Table I

Data on the characteristics of the mooring chains and free oscillations in surge and sway

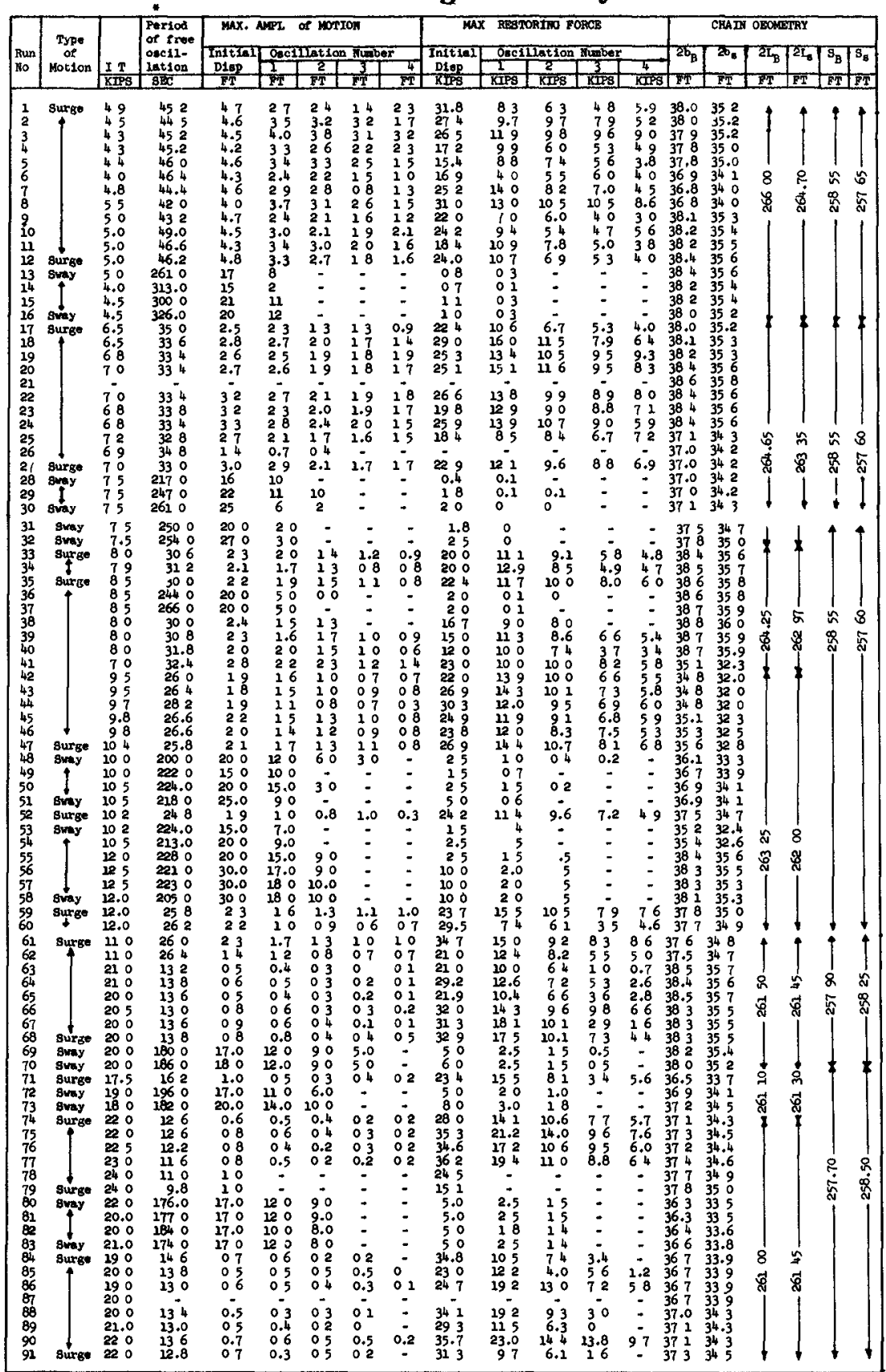

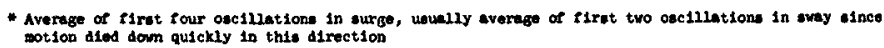


FREE OSCILLATION IN SURGE AND SWAY OF A MOORED FLOATING DRY DOCK
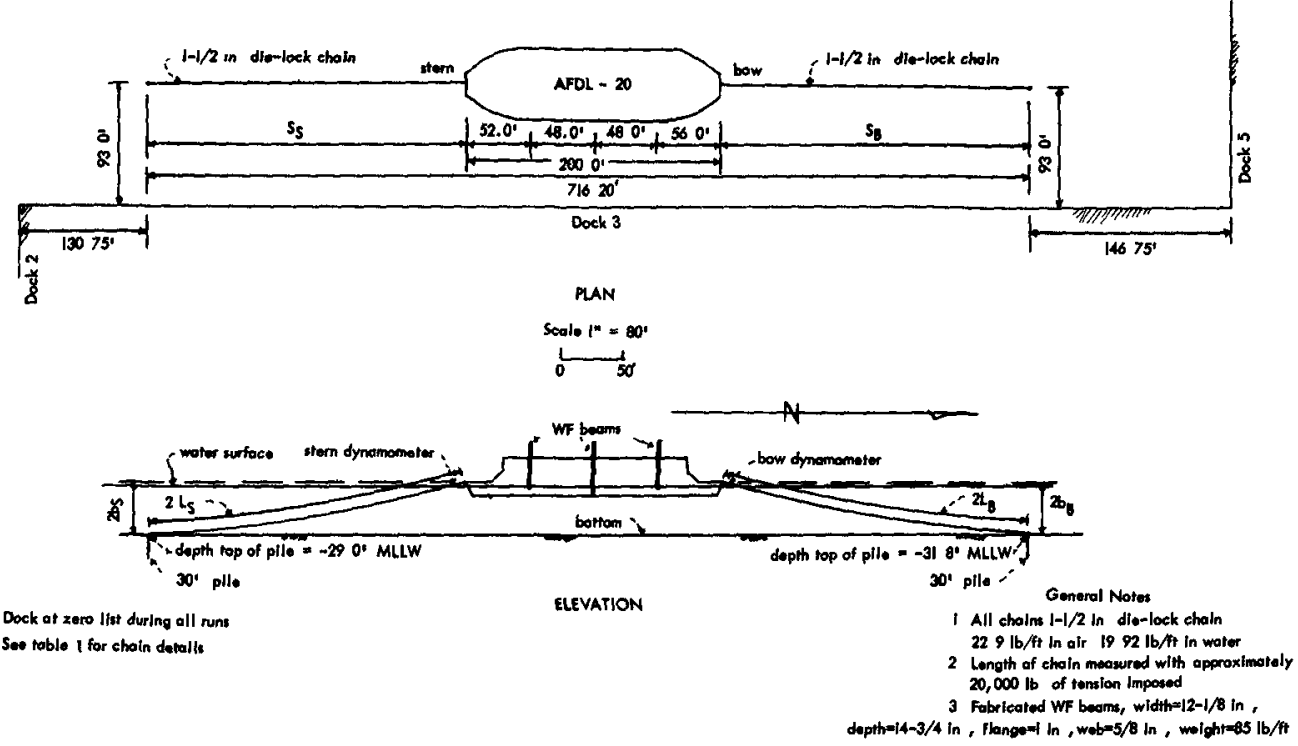

Fig. 1. AFDL-20 as moored during study.
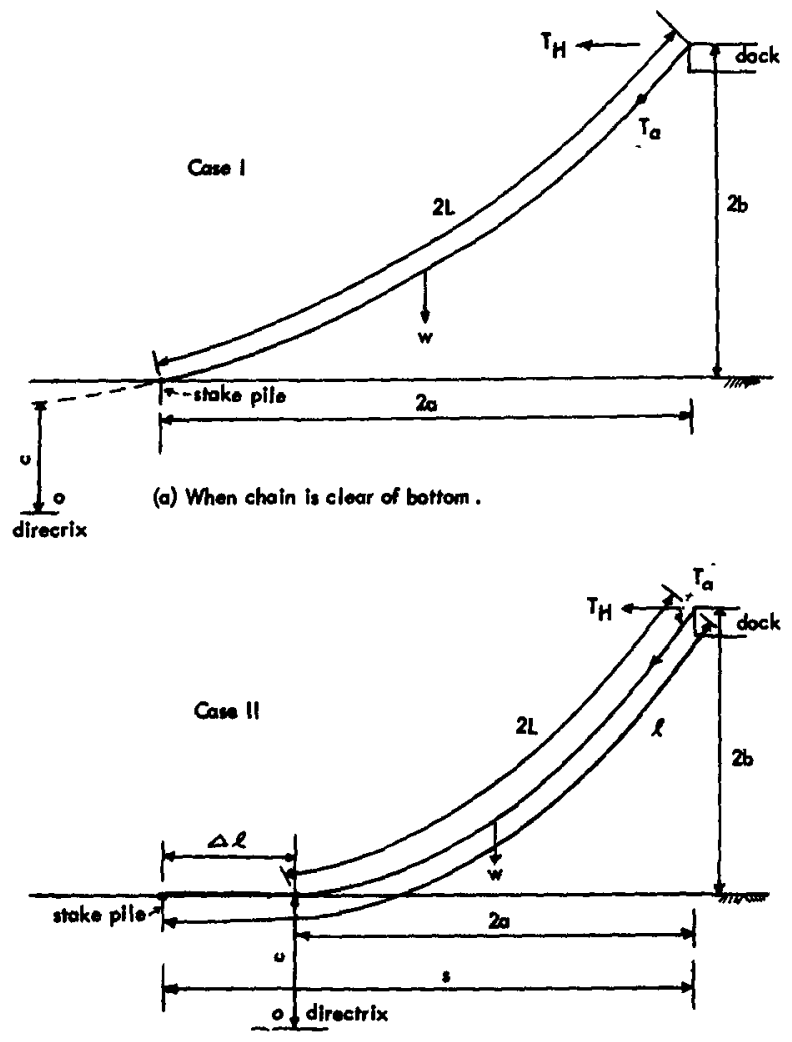

(b) When a portion of chaln is on bottom.

Fig. 2. Basic geometry of mooring chains. 


\section{ANALYTICAL CONSIDERATIONS*}

The condition of force eq uilibrium on the Dock in either surge or sway is considered to be:

$$
\text { Inertla }+ \text { damplng }+ \text { restoring force }=0 \ldots \ldots \ldots \text { (1) }
$$

where the sigit for each ferm is determined by the performance of the system as a who

The inertial reaction is made up of two parts? that of the Dock and that of the hydrodynamic mass of the Dock - added mass effect -- where in the case of surge $(x)$ :

$$
\text { Inertle force }=m\left(1+C_{m}\right) d^{2} x / d t^{2}
$$

$C_{m}$ is the inertial coefficient (ratio of hydrodymamic mass to the displaced mass). In most cases the term $\left(1+C_{m}\right)$ is written as $C_{M}$ and is termed the mass factor. Thus

$$
\text { Inertia force }=C_{M} m \ddot{x}
$$

The damping reaction is based on the well known expression:

$$
\text { damping force }=C_{D} A \rho(\dot{x})^{2} / 2 \ldots \ldots \ldots \ldots \ldots
$$

where in the case of laminar flow the velocity term ( $\ddot{x}$ ) may be treated as linear rather than squared. A is the projected underwater area of the vessel for form drag and the wetted area of the vessel for frictional drag.

The restoring force $F(x)$ consists only of that due to the weight of the chains, since in no case are the movements of the Dock large enough to cause the chain to elongate. While in all cases the cha in obviously hangs in a catenary, it is necesso to consider two definite attitudes which are dictated mainly by the initial tension namely: Case I (Flgure 2-a) where the chain is suspended entirely between the anchor and the Dock and the low point of the curve describing the system is locate below the bottom of the Harbor with a run from the directrlx which is greater than that of the chain proper; Case II (Flgure 2-b) where some portion of the chain rests on the bottom such that the low point is located there with a run e qual to that of $t$ suspended portion.

For Case $I$ the suspended length (2L) of the chain, its run (2a) rise (2b) and unlt weight $(w)$ are measured. In Case 11 in addition to $2 b$ and $w$ the total length $(\ell)$ is measured and the run (2a) is assumed. This run is substracted from the horizontal distance $(s)$ between anchor and Dock ends of chain to permit an estime of the portion of the chain $(\Delta l)$ considered to be resting on the bottom. The estimated length (2L) of the suspended portion of the chain is obtained from the expression: $2 L=l-\Delta l$. This assumption is checked analytically as outlined below and by such "cut and iry" procedure a fI rm value for $2 \mathrm{~L}$ is obtained.

The restoring force in elther surge or sway is the algebraic sum of the horiz components of the tension in the Dock end of the chain. In Case I the determina * See list of symbols p.893 


\section{FLOATING DRY DOCK}

of the component $\left(T_{H}\right)$ through use of the catenary equations as outlined by Marks (1930) is straightfor ward as follows:

$$
(\sinh z) / z=\left(L^{2}-b^{2}\right)^{1 / 2} / a
$$

where $z$ is a parameter as defined in equation (4) and determined by cut and try procedure using the measured values of $L, b$ and $a$. Then:

$$
c=a / z
$$

where $c$ is the vertical distance from the low point on the chain to the directrix (Figure 2-a). With this value the horizontal component $\mathrm{T}_{\mathrm{H}}$ can be obtalned simply as:

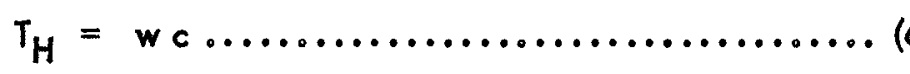

Because the chain tension $(T)$ and not its horizontal component is measured it is necessary as a check to calculate this from' the relationship:

$$
T=w\left(c+y_{0}+b\right)
$$

where $y_{0}$ is the vertical distance from the midpoint of the line connecting the anchor and Dock ends of the chain to the low point on the catenary system (FI gure 2-a) such that:

$$
y_{0}=(L / \tanh z)=c
$$

The horizontal distance $x_{0}$ corresponding to $y_{0}$ is given by:

$$
x_{0}=c \tanh ^{-1}(b / L)
$$

For Case II, it is necessary after computing the distance from the directrix to low point on chain (c) on the basis of equation (5) to calculate the run (2a) to determine whether or not this checks the assumed value. This is done on the basis of the relationship:

$$
2 a=c \sinh ^{-1} 2 \mathrm{~L} / \mathrm{c}
$$

When the assumed and calculated runs ogree then the chain tension at the Dock end and Its horizontal component are calculated as in Case I.

In general, as indicated by a consideration of the catenary equatlons, the relatlonship between restoring force and movement will be non-linear such that for iurge:

$$
\begin{aligned}
F(x)=\text { restoring force } & =k x^{n} \ldots \ldots \ldots \ldots \\
& =T_{H} \text { bow }-T_{H} \text { Stern }
\end{aligned}
$$


where $k$ is the spring factor, $x$ the movement in surge and $n$ an exponent defining the non-linearity of the moorings.

In the case of sway:

$$
F(x)=T_{H} \text { bow }(\cos \alpha)+T_{H} \text { stern }(\cos \alpha) \ldots \ldots \ldots
$$

where $\alpha$ is the horizontal angle between the chain and the direction of motlon (sway).

The natural period of ascillation in surge or sway is obtained by a solution of equation (l) In the form of an expression for movement as a function of time such that the period - time between two successive peaks - can be evaluated. Because the restoring force is in general non-linear with movement, such a method demands the solution of a non-linear differential equation which is best accomplished by numerical methods utilizing machine computation.

If damping and added mass effects are neglected, graphical methods as outline for example by Timoshenko (1937) may be used to abtain the natural period $\left(T_{n}\right)$ whic will vary of cours e with amplitude of initial displacement. Thus from equation (l):

$$
\mathbf{m} \ddot{\mathbf{x}}=\boldsymbol{F}(\mathbf{x})
$$

where graphical methods or the equivalent must be used when $F(x)$ is non-linear. However, when $F(x)$ is linear then the natural period from equation (14) is the very familiar:

$$
T_{n}=2 \pi(m / k)^{l / 2} \ldots \ldots \ldots \ldots \ldots \ldots \ldots \ldots \ldots
$$

\section{ANALYTICAL RESULTS}

The relationships between restoring force and movement was calculated by $u$ of equations (12), (13) and (4) through (10) for three initial tensions with results of the type shown in Figures 3 and 4. The relationshlp is found to be non-linear althe depending upon the initial tension, there is in all cases a range over which this non-linearity is very weak.

The natural periods of oscillation for particular conditions of restoring force versus movement were calculated by means of graphical intergrations of restoring force-displacement curves such as those in Figures $3 \& 4$ on the basis of equation ( It was assumed that the added mass effect is negligible - this is substantiated by experiment - and that the damping can be neglected in a consideration of natura perlod. Such an analysis (Figures 5 and 6) indicates that for any particular Initial tension the natural period varles Inversely with the initial displacement in a nonlinear manner.

If the nearly linear restoring force-displacement range is considered then it rewarding to study the relationship between the natural period $\left(T_{n}\right)$ and Initial ten (IT) only. The results of such a study are presented in Figures 7 and 8 where the $c$ 
FREE OSCILLATION IN SURGE AND SWAY OF A MOORED

\section{FLOATING DRY DOCK}

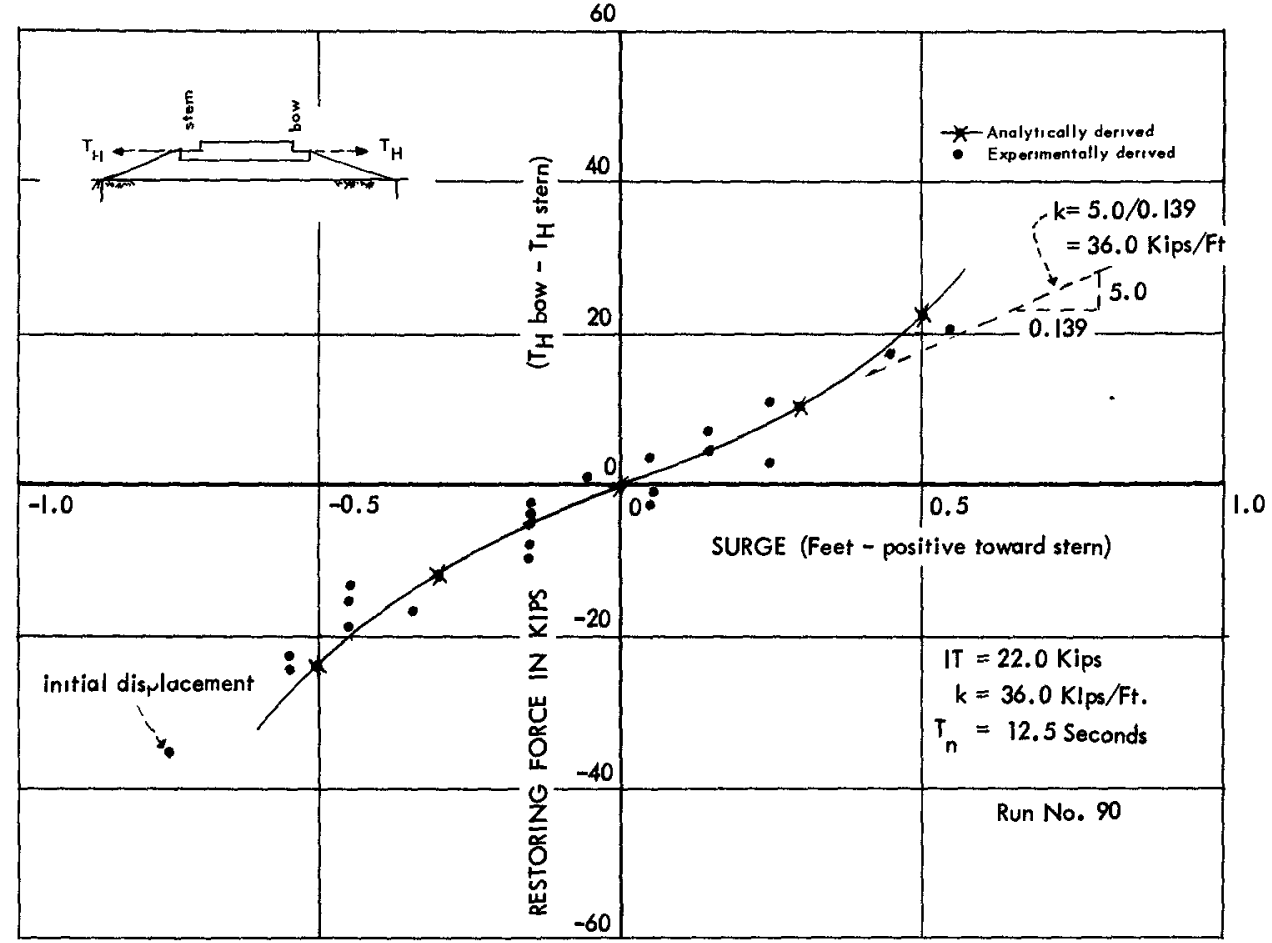

Fig. 3. Restoring force versus surge for a high initial tension.

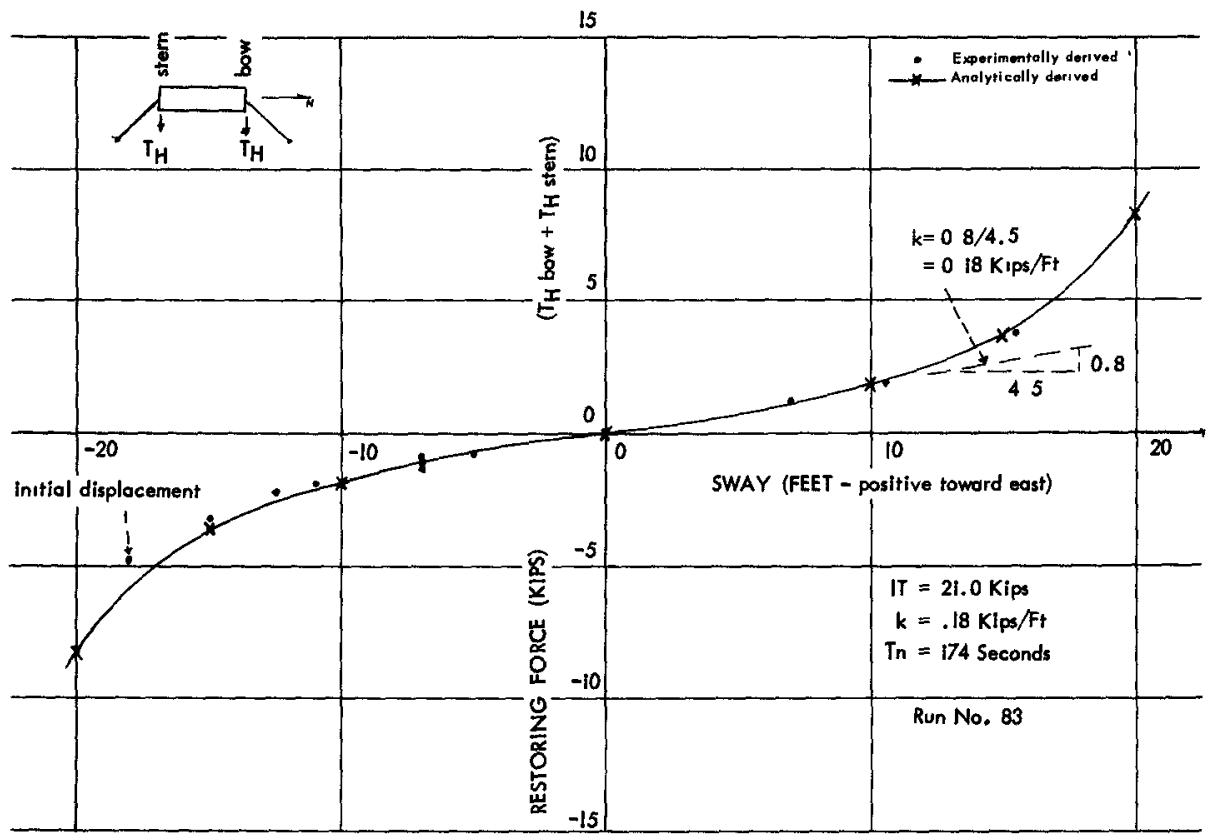

Fig. 4. Restoring force versus sway for a high initıal tensıon. 
COASTAL ENGINEERING

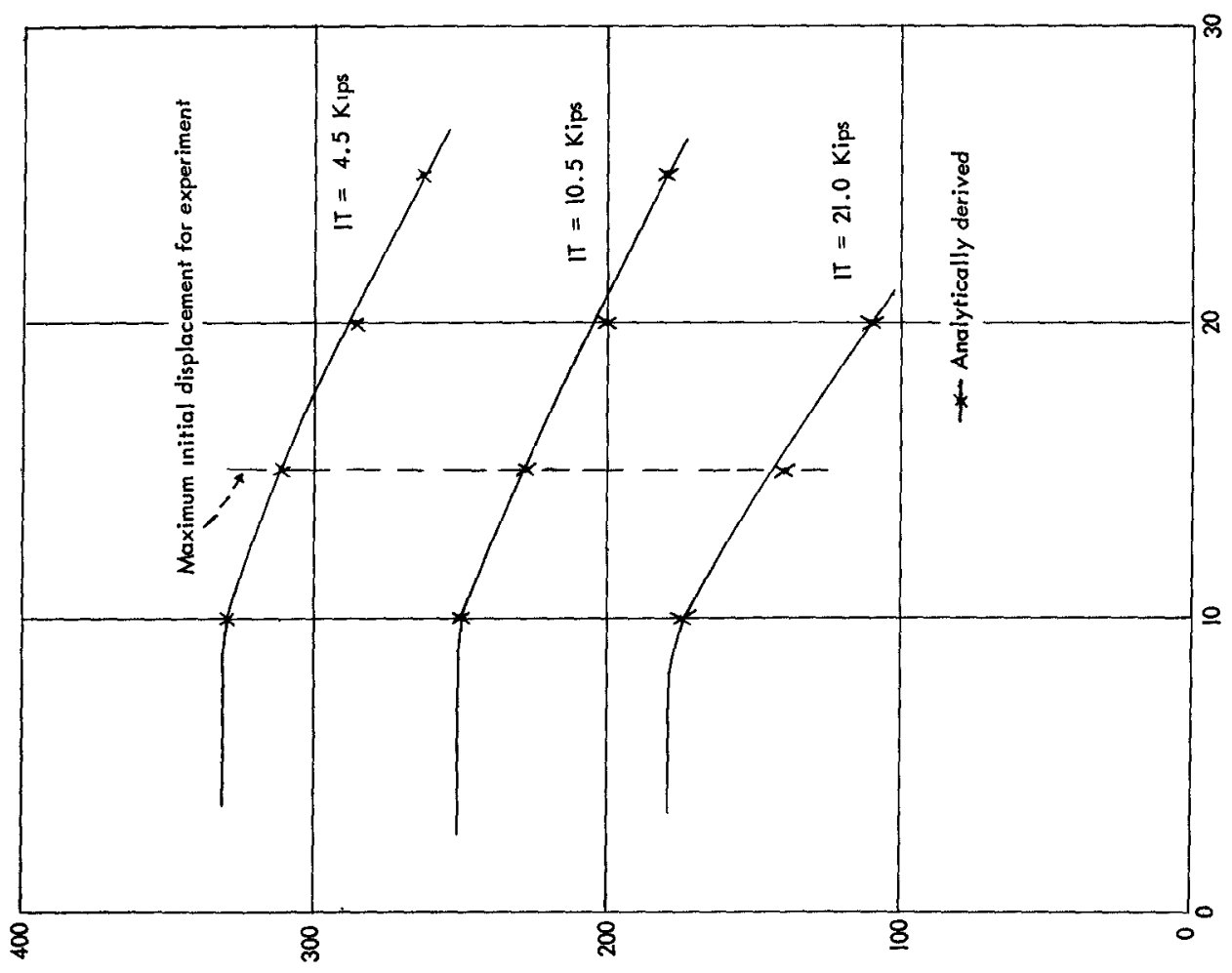

0
5
0
0
0
5
5
0
0
3

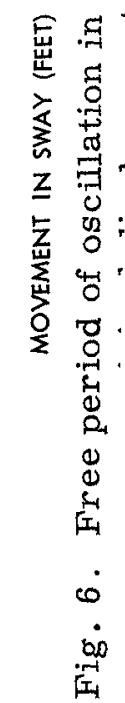

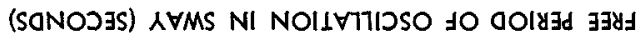

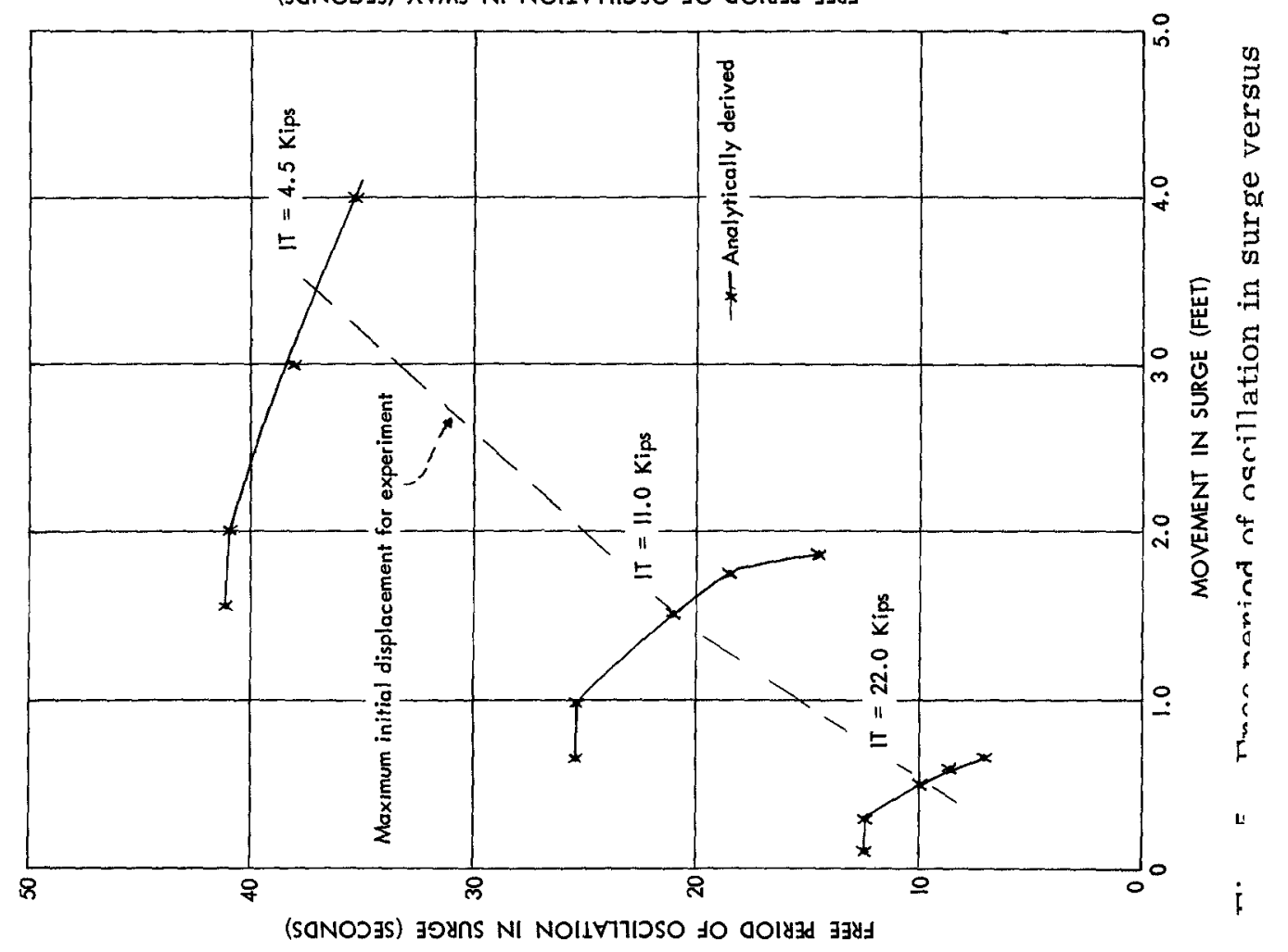




\section{FREE OSCILLATION IN SURGE AND SWAY OF A MOORED FLOATING DRY DOCK}

used to define the curves is taken from the nearly linear portlon of the curves in Flgure 5 ( $T_{n}$ of $42,25.5$ and 12.5 seconds for IT of respectively 4.5, II and $22 \mathrm{klps}$ ) and Figure $6\left(T_{n}\right.$ of 315,225 and 175 seconds for IT of respectively 4.5, 10.5 and 2l kips). It is indlcated that, within such a linear restorlng force-displacement range, the natural perlod varies inversely with initial tension such that:

$$
\begin{aligned}
& T_{n x}=55.5 / .07^{T T} \\
& T_{n y}=530 / 1 T^{0.366}
\end{aligned}
$$

where $T_{n}$ is In seconds and $I T$ is In kips and $x$ and $y$ refer respectively to surge and sway. Equatlons (I6) and (I7) are not proper when Initial displacements are into the definitely non-linear range.

It is interesting to note that by linearizing the restoring force data over a reasonable range of initial displacements and then Introducing the slope of the restoring force-displacement line as the spring factor ( $k$ ) In equation (I5) it is possible (Table II) to obtain values for the natural perlod which agree well In many cases with those obtained by more elaborate means for the true condition which is non-Ilnear.

Table II. Natural perlods computed using the true and linearized

\begin{tabular}{|c|c|c|c|c|c|}
\hline Dir. & $\begin{array}{l}\text { Run } \\
\text { No. }\end{array}$ & $\begin{array}{c}\text { initlal } \\
\text { Tenslon } \\
\text { (klps) } \\
\end{array}$ & $\begin{array}{c}\text { Initlal } \\
\text { Disp. } \\
\text { (feet) } \\
\end{array}$ & $\begin{array}{l}\text { Curve } \\
\text { Used }\end{array}$ & $\begin{array}{l}\text { Natural } \\
\text { Period } \\
\text { (seconds) }\end{array}$ \\
\hline \multirow[t]{2}{*}{ surge } & 90 & 22.0 & 0.5 & $\begin{array}{l}\text { true (non-llnear) } \\
\text { linearlzed }\end{array}$ & $\begin{array}{l}10.0 \\
12.5\end{array}$ \\
\hline & & & 0.3 & $\begin{array}{l}\text { true } \\
\text { IInearlzed }\end{array}$ & $\begin{array}{l}12.5 . \\
12.5\end{array}$ \\
\hline \multirow[t]{2}{*}{ sway } & 83 & 21.0 & 15 & $\begin{array}{l}\text { true } \\
\text { IInearlzed }\end{array}$ & $\begin{array}{l}136 \\
174\end{array}$ \\
\hline & & & 10 & $\begin{array}{l}\text { true } \\
\text { IInearlzed }\end{array}$ & $\begin{array}{l}175 \\
174\end{array}$ \\
\hline
\end{tabular}
curves of restoring force versus movement (Flgures 3 \& 4)

That reasonable agreement is obtained is due to the fact that in this study the restoring force-displacement relationshlp is not strongly non-linear over a considerable range of movements. Linearizations permit natural perlods to be computed relatively easily where the results obtalned In many cases may be well within the accuracy desired In ordinary engineering appl lcations.

A more complicated mooring system for the Dock, consisting of elght chains (I each fore and aft and 3 each port and starboard) each with a large concentrated load as described by Wiegel et al (1956) was studled analytlcally using equations (4) through (I5). The comparison between the natural periods of oscillation in both surge and sway as calculated, on the basis of the developed restoring force-displacement 


\section{COASTAL ENGINEERING}

curves, and as measured on the Model is Indicated to be very good.

\section{EXPERIMENTAL RESULTS FROM THE PROTOTYPE}

The oscillations of the Dock occurred in the range where restoring force varled in a nearly linear manner with displacement. This range varled with initial line tension being up to 0.6 and 2 feet in surge for initial tension of respectively 22 ani 4.5 kips and up to 15 feet in sway for the same initial tensions.

A very marked increase in restoring force occurred when the Dock moved into the definitely non-linear region where, although the tug used to produce initial displacement had the capability to move the Dock Into the lower part of the definitely non-linear range, the free oscillations were never sustained in this region due Iikely to the high rate of damping involved.

The results obtained are In the form of oscillograms of osclllations in force (those from the chain dynamometers) as a function of time. A facsimlle of two sucl oscillograms is presented in Figure 9. The oscillations appear to be approximately sinusoidal and to exhibit a dying down typical of a system with greater than critice damping. In the case of surge the amplitudes appear to decrease in nearly equal decrements as an arithmetical series $(.7, .5, .3, .1$, etc. feet for maximums in th case of run 190 , Figure 10). This seems to be characteristic of a Coulomb type damping - an apparent anomaly in a hydrodynamic system -- where the nonlinearity is located in the damping system.

The chain tensions, measured at the Dock end of the chain, when resolved into their horizontal components by use of measured chain slopes, give the restorli forces as expressed by equations (12) and (13). The comparis on between these values and those obtained analytically is considered in the main to be good - thi results presented in Figures 3 and 4 are examples - although there is considerabli scatter in the data in places. This is considered to reflect both the non-linear an coupled nature of the Dock movement which was not purely in either surge or swa and to certaln vagarles in the measurement of this movement by surveyors readin! from some distance on scales atfached to the moving Dock.

The magnitude of the added mass effect was evaluated at the extremes of the osclilations where the acceleration ( $\ddot{x})$ was moximum and the velocity and thus th damping was zero. For surge equations (1), (2) and (12)

$$
\begin{aligned}
C_{M} & =F(x) / m \ddot{x} \\
& =\left(T_{H} \text { bow }-T_{H} \text { stern }\right) / m \ddot{x} \ldots \ldots \ldots \ldots \ldots . . . . . .
\end{aligned}
$$

Values for the maximum acceleration were obtained by plotting the measured movements of the Dock versus time and performing the necessary two differentlal 
FREE OSCILLATION IN SURGE AND SWAY OF A MOORED

FLOATING DRY DOCK
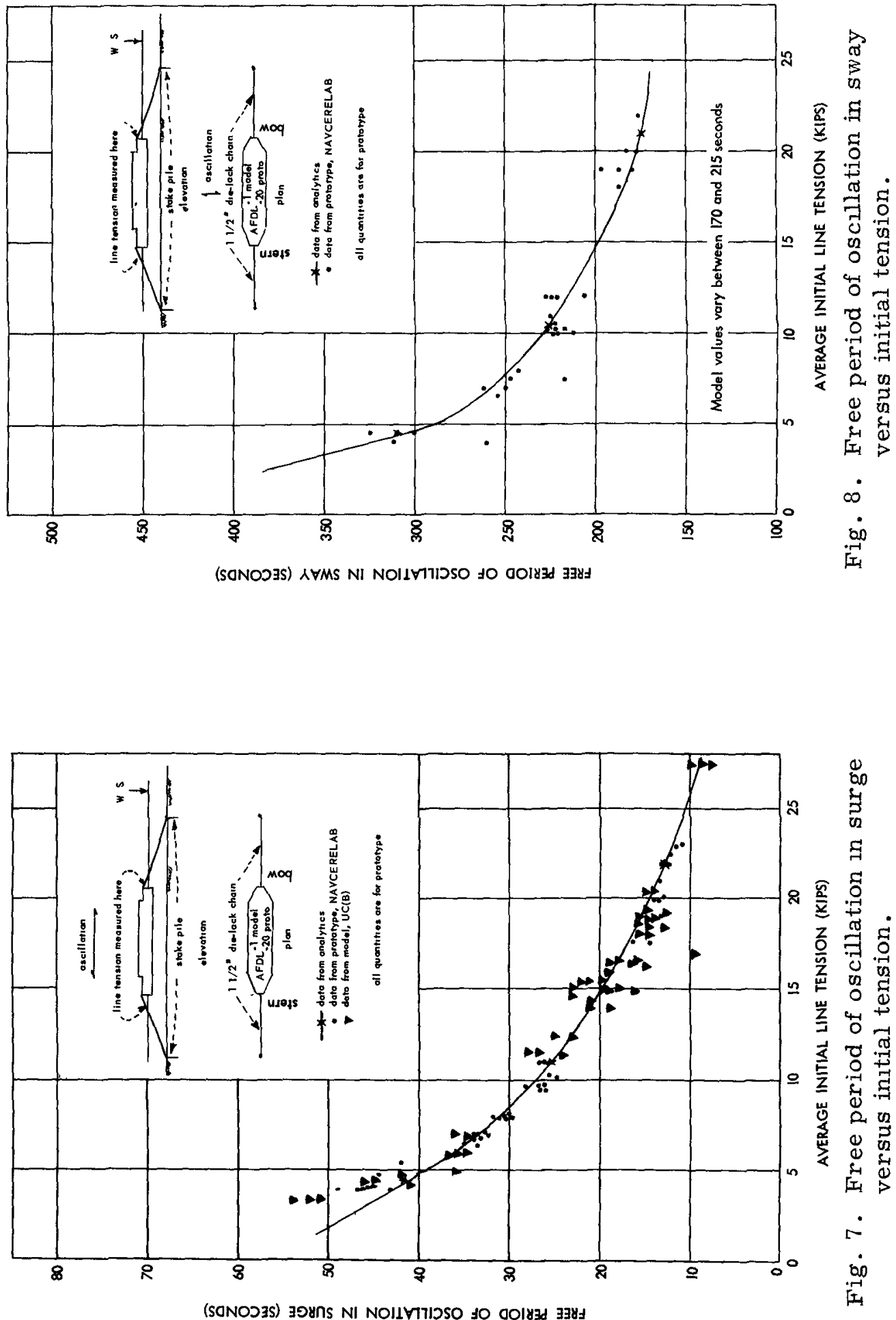


\section{COASTAL ENGINEERING}

of this curve graphlcally (Figure 10). These values along with values for the measured restoring force and mass $(m)$ when substituted in equatlon (I8) gave values for $C_{M}$ close enough to unity to permit the added mass effect to be declared negliglble in this study.

The oscillations tend to maintain themselves at a nearly constant perlod even though the amplitude of the motion tends to dle down in the manner discussed previously. This linearity of perlod with movement as well as time permits consideration of the measured periods as a function only of the initial tension. An Inverse relatlonship is indicated (FIgures 7 and 8 ) as predicted by the analytlcs. The comparison between the experiment al and analytically derlved perlods on this basis is considered good with the greatest differences occurring at the lowest initial tensions.

\section{EXPERIMENTAL RESULTS FROM THE MODEL}

The principal effort was devoted to obtaining the natural perlod of oscillation In surge as a function of initial tension and displacement. The data is contained on oscillograms of force -- that is the Dock end of the lines -- versus time. From these data the perlods were measured.

The Model values for the perlod were extrapolated to the Prototype by means $c$ the Froude Law - - a kinematical relationship which states that for Identical conditl of gravity the length ratlo is equal to the square of the time ratio - which in this study means that the natural perlods obtained in the Model were multiplied by 6.3 - the square root of the length ratio of 40 prototype to I model -- to obtain th corresponding value In the Prototype.

Movement of the Dock was not measured directly. It is recognized that this movement can be obtained by Indirect means from the force osclllograms -- this wa: done in three cases of particular interest by use of calculated curves of restoring force versus movement - but such an effort on a general basis was considered beyond the scope of this paper. However, from the limited indirect studies of movement which were made, it appears that In general the free oscillations occurre In a range of amplitudes within which the varlation of restoring force with moveme was close enough to linear to permit the Model results for period to be revlewed as functions of initial tension only.

Such a comparison is made in Figure 7 where, although the scatter is consider with the mid Initial tension, the comparison with the Prototype and analytically derived values is thought to be good with the usual inverse relationship between period and Initlal tension indicated. The scatter, besides being due to the inabil of the experimenters to cause the Dock to oscillate purely in surge, is attributed to the fact that the restoring force-displacement relationship is not truly linear 
FREE OSCILLATION IN SURGE AND SWAY OF A MOORED FLOATING DRY DOCK
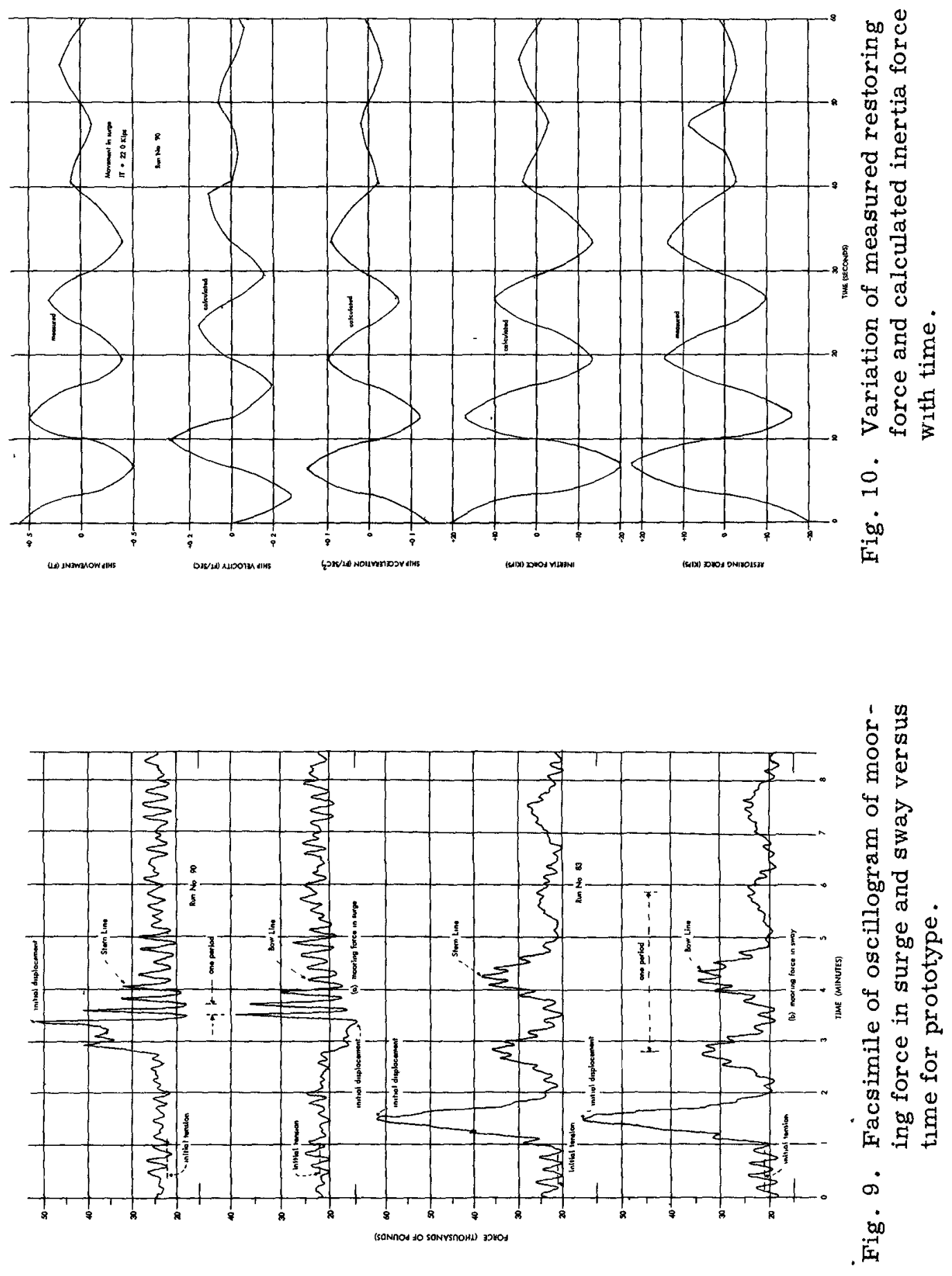


\section{COASTAL ENGINEERING}

although assumed so for this presentation and therefore for any particular initial tension there could exist many natural periods of osclllation depending upon the initial displacement given to the Dock. This same criticism is of course applicable to the Prototype and analytically derived data as presented in Figure 7 where for the latter case a serles of curves each for a particular Initial displacement could be drawn as a function of period and initial tension.

The measurement of the natural perlod in sway in the Model proved unrewarding because the unwanted damping contributed particularly by the winds in the outdoor model basin was enough to override effectively the very small restoring force provided by the chains and therefore no significant free osclllation of the Dock in this direction could be sustained for a long enough period to obtain a significant recording. Visual abservations indlcated that for a range of initial tensions of about 10 to $20 \mathrm{kips}$ the natural periods varied between 215 and 170 seconds which is considered to confirm roughly those obtained from the Prototype and analytics (Figure 8).

On the basis of the results obtained in surge (Figure 7 ) it is considered that it has been demonstrated that it is possible to model successfully not only the characteristics of the Dock itself but also of the moorings in the manner described by Wiegel et al (1956).

\section{CONCLUSIONS}

For the Dock as spread moored by a single chain of 8 scope, respectively, fore and aft and oscillating in either surge or sway it is concluded that:

1. The natural period of oscillation calculated as a function of amplitude and initial tension by use of the catenary equations and graphical intergration of the well known spring-mass equation, checks the experimentally determined values to a sensible degree of accuracy where damping and the added mass effect are neglected. Such calculations are sultable for design purposes; much more complicated mooring systems can be treated in the same manner.

2. Restoring force varies with movement in a non-linear manner. For small movements -- maximum of $I / 2$ and 6 feet for initial tensions of respective $y 22$ and 4.5 kips -- this relationship can be linearized without significant loss of accuracy for use in the equation:

$$
T_{n}=2 \pi(m / k) \cdot 1 / 2
$$

3. The natural period $\left(T_{n}\right)$ in surge $(x)$ and sway $(y)$ varles inversely in a nonlinear manner with initial tension (IT) such that for relatively small oscillations $T_{n x}=55.5 / 1.07 / T$ and $T_{n y}=530 / 1 T^{0.366}$ where $T_{n}$ is in seconds and $I T$ in 
FREE OSCILLATION IN SURGE AND SWAY OF A MOORED

\section{FLOATING DRY DOCK}

klps. This period varles also with the amplitude of oscillation so that for relatively large oscillations the expressions given do not hold.

4. The natural perlods as obtained from oscll lating a I to 40 linear scale Model in surge confirm to sensible degree those obtalned from the Prototype and by analytics; the Model results in sway are not as extensive as in surge but also tend to conflim the Prototype results. On the basis of the surge data it is concluded that the characteristics of a ships mooring lines can be modeled satisfactorily.

\section{ACKNOWLEDGEMENTS}

Appreclation is expressed to the U. S. Naval Clvil Engineering Research and Evaluation Laboratory of the Bureau of Yards and Docks for permission to publish this paper.

\section{REFERENCES}

I. O'Brien, J. T., Jones, R. E. (1956) A Prototype Mooring Force Meter, Proc. First Conf. on Coastal Engineering Instruments, U. of Californla (B).

2. Wlegel, R. L., Dilley, R. A., Clough, R. W., Williams, J. B. (1956) Model Study of Ship Mooring Forces; final report, Serles 92 Issue 8, Wave Research Laboratory U. of California (B).

3. Marks, L. S. (1930) Mechanical Engineers' Handbook, McGraw-HIII Book Co. Inc. New York and London.

4. Timoshenko, S. (1937) Vibration problems in engineering, D. Van Nostrand Co. Inc. New York pp 12I.

\section{SYMBOLS}

$A=$ Project underwater area of vessel for form drag

$=$ Wetted area of vessel for frictional drag

$2 a=$ Run of chain

$2 b=$ Rise of chain

c = Vertical distance from low point on the chain to the directrix in the catenary system

$C_{D}=$ Coefficient of drag

$C_{m}=$ Inertial coefficient 
$C_{M}=$ Mass factor

$F(x)=$ Restoring force

$\mathrm{g}=$ Acceleration due to gravity

$k \quad=$ Spring factor $=$ ratio of restoring force to movement

$2 \mathrm{~L}=$ Suspended length of chain

$\ell=$ Total length of chain

$\Delta \ell=$ Portion of chain resting on the harbor bottom

$\mathrm{m}=$ Mass of vessel

$n=$ Exponent defining the non-linearity of the moorings

s = Horizontal distance between anchor and Dock ends of mooring chains

$T=$ Chain tension

$T_{H}=$ Horizontal component of chain tension

$T_{n}=$ Period of oscillation

IT = Initial chain tension

$w=$ Unit weight of chain

$y=$ Movement in sway

$x \quad=$ Movement in surge

$x_{0}=$ Horizontal distance corresponding to $y_{0}$

$y_{0}=$ Vertical distance from the midpoint of the line connecting anchor $c$ vessel ends of the chain to the low point on the catenary system

$z=$ Catenary parameter $=a \sinh z /\left(L^{2}-b^{2}\right)^{1 / 2}$

$\propto=$ Horizontal angle between the chain and the direction of motion

$d^{2} x / d t^{2}=$ Acceleration of vessel $=\ddot{x}$

$\mathrm{dx} / \mathrm{dt}=$ Velocity $=\dot{x}$

$\rho=$ Density of water 